\title{
Utilização da Fitase em Dietas com ou sem Farelo de Arroz Desengordurado para Suínos em Crescimento/Terminação
}

\author{
Maria do Carmo Mohaupt Marques Ludke ${ }^{1}$, Jorge López ${ }^{2}$, Jorge Vitor Ludke ${ }^{3}$, \\ Sérgio Nicolaiewsky ${ }^{4}$
}

\begin{abstract}
RESUMO - Este trabalho foi conduzido com o objetivo de comparar a eficiência de diferentes níveis de fitase em relação à suplementação de fosfato inorgânico (fosfato bicálcico), quando adicionados em dietas sem e com farelo de arroz desengordurado (FAD). Foram utilizados 128 suínos com peso inicial médio de $21,2 \pm 2,4 \mathrm{~kg}$, alojados em baias coletivas, para avaliar o desempenho nas fases de crescimento e terminação. Os suínos foram abatidos com peso médio de 95,4 $\pm 5,3 \mathrm{~kg}$ e coletado o osso metacarpo para determinação do cálcio e do fósforo. Foram usados oito tratamentos, sendo quatro dietas sem FAD (milho e farelo de soja) e quatro dietas com 30\% de inclusão de FAD, nas quais foram adicionados níveis de 0,750 ou $1000 \mathrm{UF}$ (Unidades de Fitase)/kg. Foi observado que adicionar fitase, tanto em dietas sem FAD quanto em dietas com FAD, melhora a disponibilidade do fósforo orgânico. Com os níveis de 750 e 1000 UF/kg adicionados em ambas as dietas, sem suplementação de fosfato bicálcico, não houve prejuízo sobre o desempenho dos animais. Entretanto, as características ósseas são prejudicadas se as dietas com fitase não forem suplementadas com a fonte de fósforo inorgânico.
\end{abstract}

Palavras-chave: cálcio, disponibilidade, enzima, fitato, fósforo

\section{Use of Phytase in Diets with or without Defatted Rice Bran for Growing/Finishing Pigs}

\begin{abstract}
The objective of this work was to compare the efficiency of different levels of phytase with the use of inorganic phosphate (dicalcium phosphate) when added to diets with or without defatted rice bran (DRB). One hundred and twenty eight pigs with average initial weight of $21.6 \pm 2.4 \mathrm{~kg}$ were housed in collective boxes for the pig performance evaluation in the growing and finishing phase. The pigs were slaughtered with an average weight of $95.42 \pm 5.3 \mathrm{~kg}$ and the metacarpus bones were collected to determine the calcium and phosphorus content. Eight treatments were used with four diets being formulated without DRB (cornsoybean meal) and the other four diets with DRB. The phytase levels added in the diets were 0,750 or $1000 \mathrm{PU} / \mathrm{kg}$ of the diet. It was observed that adding phytase in diets without and with DRB improved the availability of the organic phosphorus. The addition of phytase at levels of 750 or $1000 \mathrm{PU} / \mathrm{kg}$, with or without DRB in the diet, allows the withdraw of the inorganic phosphorus source from diet if considering pig performance. However, the bone characteristics are affected when the diets with phytase were not supplemented with a source of inorganic phosphorus.
\end{abstract}

Key Words: availability, calcium, enzyme, phosphorus, phytate

\section{Introdução}

A maior parte das dietas para suínos e aves são compostas por milho e farelo de soja, porém um alimento que pode substituir parcialmente o milho é o farelo de arroz desengordurado (FAD).

Éumingrediente resultante da extração por solvente da gordura do farelo de arroz integral para a produção de óleo comestível (Oliveira \& Molina, 1981). Possui alto teor de proteína bruta, extrativo não-nitrogenado e alta quantidade de fósforo total, cerca de 2,13\% (Embrapa,
1985), apesar deste último ser altamente indisponível para os não-ruminantes. Segundo Assada \& Kasai (1962), no estádio inicial do amadurecimento do grão, a maior porção de mio-inositol está na forma de esterfosfato e que representa $80 \%$ do total do fósforo na planta. Especificamente $2 \%$ da parte externa do grão contém 23 vezes mais ácido fítico (fitato) que o grão intacto, e a remoção de $13 \%$ da superfície do grão resulta em um endosperma sem ácido fítico detectável, o que explica o alto teor de fósforo contido no farelo de arroz, porém sendo a maior parte indisponível.

\footnotetext{
${ }^{1}$ Zootecnista, DSc., Professora Adjunta de Nutrição de Não Ruminantes do Departamento de Zootecnia da Universidade Federal Rural de Pernambuco - UFRPE. R. Dom Manuel de Medeiros, s/n, Bairro Dois Irmãos. CEP:52171-900 - Recife - PE. E.mail: mcludke@uol.com.br Autora para correspondência.

2 Engenheiro-Agrônomo, PhD, Professor Titular de Nutrição Animal na Faculdade de Agronomia da Universidade Federal do Rio Grande do Sul (UFRGS).

3 Engenheiro-Agrônomo, DSc., Pesquisador de Nutrição de Suínos na Embrapa Suínos e Aves. E.mail: jorge@cnpsa.embrapa.br

4 Engenheiro-Agrônomo, MS., Professor Adjunto de Suinocultura na Faculdade de Agronomia da UFRGS. E.mail: nicola@vortex.ufrgs.br
} 
O fitato é um composto constituído com o grupo ortofosfato que é altamente ionizado e complexa com alguns cátions ( $\mathrm{Ca}, \mathrm{Mg}, \mathrm{Mn}, \mathrm{Cu}$, etc). Devido a ocorrência deste fator antinutricional para os não-ruminantes nos alimentos de origem vegetal torna-se necessária a suplementação de fósforo através de uma fonte inorgânica, que geralmente está presente nas dietas em quantidades um pouco acima da exigência do animal com o objetivo de se ter uma margem de segurança em relação à este elemento na dieta. Com isso, o fósforo fítico de baixa disponibilidade para estes animais, juntamente com este excesso de fósforo inorgânico adicionado às rações são eliminados nas fezes dos animais, ocasionando assim, problemas ambientais. Miller et al. (1991) afirmaram que a quantidade de fósforo e cálcio absorvidos é dependente principalmente dos seus níveis na dieta e de suas fontes.

A literatura mostra alguns métodos de remoção do fitato dos alimentos, tais como processos mecânicos, autoclave, diálise e diferencial de solubilidade (Cheryan, 1980). Muitos pesquisadores têm estudado a hidrólise do fitato por ação enzimática, mais especificamente pela fitase. Segundo Newman (1991), a reação catalizada pela fitase é a seguinte: Em uma solução contendo o complexo mio-inositol-hexafosfato dissolvido em água, ao adicionar a enzima fitase este complexo é dissociado dando como produtos os compostos mio-inositol-penta, tetra, tri, di e monofosfato somado ao ortofosfato inorgânico.

Segundo Kornegay (1996), a magnitude de resposta da fitase microbiana é influenciada pelo nível de fósforo total e disponível (incluindo o fósforo fítico) na dieta, pela quantidade de fitase suplementada e pela relação cálcio e fósforo. Segundo Liu et al. (1998), reduzindo a relação Ca:P para 1,0:1,0 aumenta a utilização do fósforo em suínos em crescimento e terminação alimentados com dietas à base de milho e farelo de soja, com baixo teor de fósforo e suplementadas com fitase microbiana. Alta concentração de cálcio na dieta aumenta o pH do conteúdo intestinal, diminuindo a atividade da fitase (Sandberg et al., 1993) e o cálcio extra poderia diretamente omitir a atividade da enzima por competir com o sítio ativo desta (Quian et al., 1996).

Pelo exposto acima, o objetivo deste trabalho foi avaliar diferentes níveis de fitase em dietas contendo ou não o ingrediente alternativo FAD sobre o aumento da disponibilidade dos macrominerais fósforo e cálcio para os animais. Além disso, objetivou-se observar se há necessidade de suplemento inorgânico de fósforo (fosfato bicálcico) em dietas que contenham a enzima fitase.

\section{Material e Métodos}

O trabalho experimental foi conduzido nas instalações da AVIPALS. A. localizada no município de Porto Alegre - RS no período de 15 de fevereiro a 22 de maio de 1997. Sendo um período de 42 dias para cada fase (crescimento e terminação) e um intervalo de 12 dias.

Foram utilizados 128 leitões mestiços, sendo 50\% machos castrados e $50 \%$ fêmeas com peso médio inicial de 21,2 $\pm 2,4 \mathrm{~kg}$ e peso médio final de 95,4 $\pm 5,3$ $\mathrm{kg}$. Estes animais foram alojados em 32 baias coletivas ( 4 animais/baia) e separados por sexo, sendo 16 baias para machos castrados e 16 baias para fêmeas. Antes de dar início a fase de terminação foi retirado um animal/baia considerado de peso mais discrepante dos demais, com a finalidade de iniciar a fase de terminação com o peso mais homogêneo possível dentro da unidade experimental. Foram abatidos os três animais/ baia no final do experimento, objetivando coletar o osso metacarpo para determinação de cálcio e fósforo. $\mathrm{O}$ procedimento das análises dos macrominerais foi segundo descrito por Fick et al. (1976) e pelo AOAC (1984). As análises foram realizadas no laboratório de análises de físico-química da Embrapa Suínos e Aves, localizado em Concórdia - SC.

As dietas experimentais foram preparadas a base de milho, farelo de soja e contendo ou não $30 \%$ de FAD, suplementadas com minerais e vitaminas de acordo com as recomendações mínimas do NRC (1988), tendo como fonte inorgânica o fosfato bicálcico. A composição dos ingredientes está na Tabela 1.

A adição de fitase nas dietas, em ambas as fases de crescimento e terminação, seguiu a mesma proporção existente entre a unidade da enzima e o suplemento inorgânico, ou seja, de acordo com a BASF S/A, a atividade de 500 UF (Unidade de Fitase) é equivalente a $1,15 \mathrm{~g}$ de fósforo disponível do fosfato bicálcico. A partir daí estabeleceu-se quanto deste suplemento inorgânico deveria ter a dieta, de acordo com a unidade da enzima utilizada. A concentração de cálcio foi reduzida, apresentando sempre uma relação de 1,2:1 (cálcio: fósforo), em dietas à base de milho e farelo de soja.

No entanto, as dietas com farelo de arroz desengordurado não permitiram esta mesma relação, em razão deste ingrediente apresentar alta concentração de fósforo total $(2,02 \%)$. Com isso, foi adotado o critério dos níveis de cálcio destas dietas serem iguais àquelas com milho e farelo de soja, ou seja, as dietas com 500 ou com 750 UF/kg tiveram níveis de

R. Bras. Zootec., v.31, n.5, p.2002-2010, 2002 
Tabela 1 - Composição ${ }^{1}$ dos ingredientes utilizados nas dietas experimentais.

Table 1 - Composition of the ingredients used in the experimental diets

\begin{tabular}{|c|c|c|c|c|c|c|}
\hline \multirow[t]{2}{*}{$\begin{array}{l}\text { Nutrientes } \\
\text { Nutrients }\end{array}$} & \multicolumn{6}{|c|}{$\begin{array}{l}\text { Ingredientes } \\
\text { Ingredients }\end{array}$} \\
\hline & $\begin{array}{c}\text { Milho } \\
\text { Corn }\end{array}$ & $\begin{array}{c}\text { Farelo de soja } \\
\text { Soybean meal }\end{array}$ & $\begin{array}{l}\text { FAD } \\
D R B\end{array}$ & $\begin{array}{c}\text { Óleo de soja } \\
\text { Soybean oil }\end{array}$ & $\begin{array}{l}\text { Calcáreo } \\
\text { Limestone }\end{array}$ & Ipifosc $20^{2}$ \\
\hline $\begin{array}{l}\text { Proteína bruta }(\%) \\
\text { Crude protein }(\%)\end{array}$ & 8,00 & 44,00 & 14,00 & 0,00 & 0,00 & 0,00 \\
\hline $\begin{array}{l}\text { Lisina }(\%) \\
\text { Lysine }(\%)\end{array}$ & 0,24 & 2,75 & 0,61 & 0,00 & 0,00 & 0,00 \\
\hline $\begin{array}{l}\text { Metionina }(\%) \\
\text { Methionine }(\%)\end{array}$ & 0,17 & 0,61 & 0,26 & 0,00 & 0,00 & 0,00 \\
\hline $\begin{array}{l}\text { Triptofano }(\%) \\
\text { Tryptofan }(\%)\end{array}$ & 0,04 & 0,60 & 0,21 & 0,00 & 0,00 & 0,00 \\
\hline $\begin{array}{l}\mathrm{EM}(\mathrm{kcal} / \mathrm{kg})^{3} \\
M E(\mathrm{kcal} / \mathrm{kg})\end{array}$ & 3350 & 3220 & 2865 & 7234 & 0,00 & 0,00 \\
\hline $\begin{array}{l}\text { Gordura bruta (\%) } \\
\text { Crude fat (\%) }\end{array}$ & 3,65 & 1,16 & 2,40 & 95,40 & 0,00 & 0,00 \\
\hline $\begin{array}{l}\text { Fibra bruta }(\%) \\
\text { Crude fiber }(\%)\end{array}$ & 1,70 & 5,87 & 12,90 & 0,00 & 0,00 & 0,00 \\
\hline $\begin{array}{l}\text { Cálcio }(\%) \\
\text { Calcium }(\%)\end{array}$ & 0,02 & 0,27 & 0,85 & 0,00 & 36,00 & 20,50 \\
\hline $\begin{array}{l}\text { Fósforo total }(\%) \\
\text { Total phosphorus }(\%)\end{array}$ & 0,28 & 0,65 & 2,02 & 0,00 & 0,04 & 20,00 \\
\hline $\begin{array}{l}\text { Fósforo disponível }(\%)^{3} \\
\text { Available phosphorus (\%) }\end{array}$ & 0,08 & 0,27 & 0,60 & 0,00 & 0,04 & 20,00 \\
\hline
\end{tabular}

1 Valores analisados pela AVIPAL S/A (Analyzed values AVIPAL S/A).

2 Fosfato bicálcico (Dicalcium phosphate)

3 Valores tabelados (NRC, 1988) (Table values - NRC, 1988).

cálcio de 0,49 e 0,43 , respectivamente tanto para as dietas sem FAD como às com FAD. O motivo de realizar este critério foi devido a ação negativa do cálcio sobre a ação da fitase, por isso não se quis elevar a concentração de cálcio para que a relação fosse 1,2:1 nas dietas com FAD, pois já é comprovado na literatura que com a presença de níveis muito elevados de cálcio nas dietas ocorrerá a redução na ação da enzima sobre o complexo fitato.

As rações foram isoprotéicas com $16 \%$ e $14 \%$ de proteína bruta nas fases de crescimento e terminação, respectivamente e isoenergéticas com 3300 Kcal de energia metabolizável/kg. Os tratamentos foram organizados da seguinte forma:

$\mathrm{Na}$ fase de crescimento: T1) milho e farelo de soja, com fosfato bicálcico, $0 \mathrm{UF} / \mathrm{kg}$ da dieta $(0 \%)$; T2) milho e farelo de soja, com fosfato bicálcico, 750 $\mathrm{UF} / \mathrm{kg}$ da dieta $(0,15 \%)$; T3) milho e farelo de soja, sem fosfato bicálcico, 750 UF fitase $/ \mathrm{kg}$ da dieta $(0,15 \%)$; T4) milho e farelo de soja, sem fosfato bicálcico, 1000 UF/kg da dieta (0,20\%); T5) milho, farelo de soja e 30\% FAD, com fosfato bicálcico, 0 $\mathrm{UF} / \mathrm{kg}$ da dieta (0\%); T6) milho, farelo de soja e $30 \%$
FAD, sem fosfato bicálcico, $0 \mathrm{UF} / \mathrm{kg}$ da dieta $(0 \%)$; T7) milho, farelo de soja e 30\% FAD, sem fosfato bicálcico, $750 \mathrm{UF} / \mathrm{kg}$ da dieta $(0,15 \%)$; T8) milho, farelo de soja e $30 \% \mathrm{FAD}$, sem fosfato bicálcico, $1000 \mathrm{UF} / \mathrm{kg}$ da dieta $(0,20 \%)$.

$\mathrm{Na}$ fase de terminação em todas as dietas que continham fitase (T2, T3, T4, T7 e T8) não foi preciso adicionar o suplemento inorgânico, devido a atenderem os níveis de exigência tanto para cálcio como para fósforo, sendo então, da seguinte maneira: T1) milho e farelo de soja, com fosfato bicálcico, $0 \mathrm{UF} / \mathrm{kg}$ da dieta (0\%); T2) milho e farelo de soja, sem fosfato bicálcico, $750 \mathrm{UF} / \mathrm{kg}$ da dieta $(0,15 \%)$; T3) milho e farelo de soja, sem fosfato bicálcico, $750 \mathrm{UF} / \mathrm{kg}$ da dieta $(0,15 \%)$; T4) milho e farelo de soja, sem fosfato bicálcico, $1000 \mathrm{UF} / \mathrm{kg}$ da dieta $(0,20 \%)$; T5) milho, farelo de soja e 30\% FAD, sem fosfato bicálcico, 0 $\mathrm{UF} / \mathrm{kg}$ da dieta (0\%); T6) milho, farelo de soja e $30 \%$ FAD, sem fosfato bicálcico, $0 \mathrm{UF} / \mathrm{kg}$ da dieta $(0 \%)$; T7) milho, farelo de soja e $30 \%$ FAD, sem fosfato bicálcico, $750 \mathrm{UF} / \mathrm{kg}$ da dieta $(0,15 \%)$; T8) milho, farelo de soja e 30\% FAD, sem fosfato bicálcico, $1000 \mathrm{UF} / \mathrm{kg}$ da dieta $(0,20 \%)$. 
Foi coletada uma amostra das rações de cada tratamento para análise químico-bromatológica, conforme técnicas recomendadas pelo AOAC (1984). Nas Tabelas 2 e 3 são encontradas as composições calculadas das dietas nas fases de crescimento e de terminação dos animais, respectivamente.

Foram avaliados o consumo diário de ração (CDR), ganho diário de peso (GDP), conversão alimentar (CA), peso do metacarpo seco e desengordurado (PMSD), concentração de cinzas no metacarpo (CC), concentração de fósforo no metacarpo (CP), quantidade de fósforo depositado no metacarpo (QPD), concentração de cálcio no metacarpo $(\mathrm{CCa})$ e quantidade de cálcio depositado no metacarpo (QCaD).

Tabela 2 - Composição centesimal, energética e química das dietas na fase de crescimento Table 2 - Centesimal, energy and chemical composition of the diets in the growing phase

\begin{tabular}{|c|c|c|c|c|c|c|c|c|}
\hline \multirow[t]{2}{*}{$\begin{array}{l}\text { Itens }(\%) \\
\text { Item }(\%)\end{array}$} & \multicolumn{8}{|c|}{$\begin{array}{c}\text { Tratamentos }(\%) \\
\text { Treatments }\end{array}$} \\
\hline & $\begin{array}{l}\text { Milho, } \\
\text { FS, } \\
0 \mathrm{UF}, \\
C / F B\end{array}$ & $\begin{array}{l}\text { Milho, } \\
\text { FS, } \\
750 \mathrm{UF} \\
C / F B\end{array}$ & $\begin{array}{l}\text { Milho, } \\
\text { FS, } \\
750 \mathrm{UF} \\
S / F B\end{array}$ & $\begin{array}{l}\text { Milho, } \\
\text { FS, } \\
\text { 1000UF } \\
S / F B\end{array}$ & $\begin{array}{l}\text { Milho, } \\
\text { FS, FAD, } \\
\text { OUF, } \\
C / F B\end{array}$ & $\begin{array}{l}\text { Milho, } \\
\text { FS, FAD, } \\
750 \mathrm{UF} \\
\text { S/FB }\end{array}$ & $\begin{array}{l}\text { Milho, } \\
\text { FS, FAD, } \\
750 \mathrm{UF} \\
\text { S/FB }\end{array}$ & $\begin{array}{l}\text { Milho, } \\
\text { FS, FAD, } \\
\text { 1000UF } \\
S / F B\end{array}$ \\
\hline $\begin{array}{l}\text { Milho } \\
\text { Corn }\end{array}$ & 71,71 & 71,71 & 71,71 & 71,71 & 44,67 & 44,67 & 44,67 & 44,67 \\
\hline $\begin{array}{l}\text { Farelo de soja } \\
\text { Soybean meal }\end{array}$ & 22,70 & 22,70 & 22,70 & 22,70 & 17,94 & 17,94 & 17,94 & 17,94 \\
\hline $\begin{array}{l}\text { FAD } \\
D R B\end{array}$ & 0 & 0 & 0 & 0 & 30,00 & 30,00 & 30,00 & 30,00 \\
\hline $\begin{array}{l}\text { Óleo de soja } \\
\text { Soybean oil }\end{array}$ & 2,15 & 2,15 & 2,15 & 2,15 & 4,90 & 4,90 & 4,90 & 4,90 \\
\hline $\begin{array}{l}\text { Fosfato bicálcico } \\
\text { Dicalcium phosphate }\end{array}$ & 1,15 & 0,29 & 0 & 0 & 0,43 & 0 & 0 & 0 \\
\hline $\begin{array}{l}\text { Calcáreo } \\
\text { Limestone }\end{array}$ & 1,08 & 0,97 & 0,94 & 0,94 & 0,83 & 0,48 & 0,48 & 0,29 \\
\hline $\begin{array}{l}\text { L-Lisina } \\
\text { L-Lysine }\end{array}$ & 0,26 & 0,26 & 0,26 & 0,26 & 0,28 & 0,28 & 0,28 & 0,28 \\
\hline $\begin{array}{l}\text { Premix e promotores }{ }^{1} \\
\text { Premix and promoters }\end{array}$ & 0,60 & 0,60 & 0,60 & 0,60 & 0,60 & 0,60 & 0,60 & 0,60 \\
\hline $\begin{array}{l}\text { Sal } \\
\text { Salt }\end{array}$ & 0,35 & 0,35 & 0,35 & 0,35 & 0,35 & 0,35 & 0,35 & 0,35 \\
\hline $\begin{array}{l}\text { Caulim } \\
\text { Caulim }\end{array}$ & 0 & 0,82 & 1,14 & 1,09 & 0 & 0,78 & 0,63 & 0,77 \\
\hline $\begin{array}{l}\text { Fitase } \\
\text { Phytase }\end{array}$ & 0 & 0,15 & 0,15 & 0,20 & 0 & 0 & 0,15 & 0,20 \\
\hline $\begin{array}{l}\text { Total } \\
\text { Total } \\
\text { Nutrientes (Valores calcu } \\
\text { Nutrients (Calculated value }\end{array}$ & 100 & 100 & 100 & 100 & 100 & 100 & 100 & 100 \\
\hline $\begin{array}{l}\mathrm{EM}(\mathrm{kcal} / \mathrm{kg}) \\
M E(k c a l / k g)\end{array}$ & 3.300 & 3.300 & 3.300 & 3.300 & 3.300 & 3.300 & 3.300 & 3.300 \\
\hline $\begin{array}{l}\text { Proteína bruta }(\%) \\
\text { Crude protein }(\%)\end{array}$ & 16,00 & 16,00 & 16,00 & 16,00 & 16,00 & 16,00 & 16,00 & 16,00 \\
\hline $\begin{array}{l}\text { Cálcio }(\%) \\
\text { Calcium }(\%)\end{array}$ & 0,70 & 0,49 & 0,43 & 0,43 & 0,70 & 0,49 & 0,49 & 0,43 \\
\hline $\begin{array}{l}\text { Fósforo total (\%) } \\
\text { Total phosphorus (\%) }\end{array}$ & 0,58 & 0,41 & 0,36 & 0,36 & 0,93 & 0,85 & 0,85 & 0,85 \\
\hline $\begin{array}{l}\text { Fósforo disponível (\%) } \\
\text { Available phosphorus (\%) }\end{array}$ & 0,35 & 0,18 & 0,13 & 0,13 & 0,35 & 0,27 & 0,27 & 0,27 \\
\hline $\begin{array}{l}\text { Relação Ca:P } \\
\text { Relation Ca:P }\end{array}$ & $1,2: 1$ & $1,2: 1$ & $1,2: 1$ & $1,2: 1$ & $0,75: 1$ & $0,58: 1$ & $0,58: 1$ & $0,50: 1$ \\
\hline
\end{tabular}

${ }^{1}$ Premix vitamínico/kg de ração: $5.000 \mathrm{UI}$ vit. $\mathrm{A} ; 1.000 \mathrm{UI}$ vit. $\mathrm{D}_{3} ; 10,0 \mathrm{mg}$ vit. E; $1,0 \mathrm{mg}$ vit. $\mathrm{K} ; 3,0 \mathrm{mg}$ vit. $\mathrm{B}_{2} ; 0,015 \mathrm{mg}$ vit. $\mathrm{B}_{12} ; 8,0 \mathrm{mg}$ ác. Pantotênico (Pantothenic acid); 15,0 mg niacina (Niacin); $0,05 \mathrm{mg}$ biotina (Biotin). Premix mineral/kg de raçẫo: $60 \mathrm{mg} \mathrm{Fe;} 100 \mathrm{mg} \mathrm{Zn;} 40$ $\mathrm{mg} \mathrm{Mn} ; 10 \mathrm{mg} \mathrm{Cu} ; 0,15 \mathrm{mg} \mathrm{l} ; 0,2 \mathrm{mg}$ Se. Promotores/kg de ração: 0,088 g Tylan 250; 0,1 g antioxidante (Antioxidant). 
Tabela 3 - Composição centesimal, energética e química das dietas na fase de terminação

Table 3 - Centesimal, energy and chemical composition of the diets in the finishing phase

\begin{tabular}{|c|c|c|c|c|c|c|c|c|}
\hline \multirow[t]{2}{*}{$\begin{array}{l}\text { Itens }(\%) \\
\text { Item }(\%)\end{array}$} & \multicolumn{8}{|c|}{$\begin{array}{c}\text { Tratamentos }(\%) \\
\text { Treatments }\end{array}$} \\
\hline & $\begin{array}{l}\text { Milho, } \\
\text { FS, } \\
0 \mathrm{UF}, \\
C / F B\end{array}$ & $\begin{array}{l}\text { Milho, } \\
\text { FS, } \\
750 \mathrm{UF} \\
C / F B\end{array}$ & $\begin{array}{l}\text { Milho, } \\
\text { FS, } \\
750 \mathrm{UF} \\
S / F B\end{array}$ & $\begin{array}{l}\text { Milho, } \\
\text { FS, } \\
\text { 1000UF } \\
S / F B\end{array}$ & $\begin{array}{l}\text { Milho, } \\
\text { FS, FAD, } \\
\text { OUF, } \\
C / F B\end{array}$ & $\begin{array}{l}\text { Milho, } \\
\text { FS, FAD, } \\
750 \mathrm{UF} \\
\text { S/FB }\end{array}$ & $\begin{array}{l}\text { Milho, } \\
\text { FS, FAD, } \\
750 \mathrm{UF}, \\
\text { S/FB }\end{array}$ & $\begin{array}{l}\text { Milho, } \\
\text { FS, FAD, } \\
\text { 1000UF } \\
S / F B\end{array}$ \\
\hline $\begin{array}{l}\text { Milho } \\
\text { Corn }\end{array}$ & 78,43 & 78,43 & 78,43 & 78,43 & 51,39 & 51,39 & 51,39 & 51,39 \\
\hline $\begin{array}{l}\text { Farelo de soja } \\
\text { Soybean meal }\end{array}$ & 16,97 & 16,97 & 16,97 & 16,97 & 12,22 & 12,22 & 12,22 & 12,22 \\
\hline $\begin{array}{l}\text { FAD } \\
D R B\end{array}$ & 0 & 0 & 0 & 0 & 30,00 & 30,00 & 30,00 & 30,00 \\
\hline $\begin{array}{l}\text { Óleo de soja } \\
\text { Soybean oil }\end{array}$ & 1,60 & 1,60 & 1,60 & 1,60 & 4,34 & 4,34 & 4,34 & 4,34 \\
\hline $\begin{array}{l}\text { Fosfato bicálcico } \\
\text { Dicalcium phosphate }\end{array}$ & 0,75 & 0 & 0 & 0 & 0 & 0 & 0 & 0 \\
\hline $\begin{array}{l}\text { Calcáreo } \\
\text { Limestone }\end{array}$ & 1,00 & 0,92 & 0,92 & 0,92 & 0,79 & 0,27 & 0,27 & 0,27 \\
\hline $\begin{array}{l}\text { L-Lisina } \\
\text { L-Lysine }\end{array}$ & 0,25 & 0,25 & 0,25 & 0,25 & 0,26 & 0,26 & 0,26 & 0,26 \\
\hline $\begin{array}{l}\text { Premix e promotores } 1 \\
\text { Premix and promotors }\end{array}$ & 0,60 & 0,60 & 0,60 & 0,60 & 0,60 & 0,60 & 0,60 & 0,60 \\
\hline $\begin{array}{l}\text { Sal } \\
\text { Salt }\end{array}$ & 0,40 & 0,40 & 0,40 & 0,40 & 0,40 & 0,40 & 0,40 & 0,40 \\
\hline $\begin{array}{l}\text { Caulim } \\
\text { Caulim }\end{array}$ & 0 & 0,68 & 0,68 & 0,63 & 0 & 0,52 & 0,37 & 0,32 \\
\hline $\begin{array}{l}\text { Fitase } \\
\text { Phytase }\end{array}$ & 0 & 0,15 & 0,15 & 0,20 & 0 & 0 & 0,15 & 0,20 \\
\hline $\begin{array}{l}\text { Total } \\
\text { Nutrientes (Valores calcu } \\
\text { Nutrients (Calculated value) }\end{array}$ & 100 & 100 & 100 & 100 & 100 & 100 & 100 & 100 \\
\hline $\begin{array}{l}\mathrm{EM}(\mathrm{kcal} / \mathrm{kg})^{2} \\
M E(k c a l / k g)\end{array}$ & 3.300 & 3.300 & 3.300 & 3.300 & 3.300 & 3.300 & 3.300 & 3.300 \\
\hline $\begin{array}{l}\text { Proteína bruta }(\%)^{2} \\
\text { Crude protein }(\%)\end{array}$ & 14,00 & 14,00 & 14,00 & 14,00 & 14,00 & 14,00 & 14,00 & 14,00 \\
\hline $\begin{array}{l}\text { Cálcio }(\%)^{2} \\
\text { Calcium }(\%)\end{array}$ & 0,58 & 0,40 & 0,40 & 0,40 & 0,59 & 0,40 & 0,40 & 0,40 \\
\hline $\begin{array}{l}\text { Fósforo total }(\%)^{2} \\
\text { Total phosphorus }(\%)\end{array}$ & 0,48 & 0,33 & 0,33 & 0,33 & 0,83 & 0,83 & 0,83 & 0,83 \\
\hline $\begin{array}{l}\text { Fósforo disponível }(\%)^{2} \\
\text { Available phosphorus }(\%)\end{array}$ & 0,26 & 0,11 & 0,11 & 0,11 & 0,26 & 0,26 & 0,26 & 0,26 \\
\hline $\begin{array}{l}\text { Relação Ca: } \mathrm{P}^{2} \\
\text { Relation Ca:P }\end{array}$ & $1,2: 1$ & $1,2: 1$ & $1,2: 1$ & $1,2: 1$ & $0,71: 1$ & $0,48: 1$ & $0,48: 1$ & $0,48: 1$ \\
\hline
\end{tabular}

${ }_{1}$ Premix vitamínico/kg de ração: $5.000 \mathrm{UI}$ vit. $\mathrm{A} ; 1.000 \mathrm{UI}$ vit. $\mathrm{D}_{3} ; 10,0 \mathrm{mg}$ vit. $\mathrm{E} ; 1,0 \mathrm{mg}$ vit. $\mathrm{K} ; 3,0 \mathrm{mg}$ vit. $\mathrm{B}_{2} ; 0,015 \mathrm{mg}$ vit. $\mathrm{B}_{12} ; 8,0 \mathrm{mg}$ ác. Pantotênico (Pantothenic acid); 15,0 mg niacina (Niacin); 0,05 mg biotina (Biotin). Premix mineral/kg de raçẫo: $60 \mathrm{mg} \mathrm{Fe;} 100 \mathrm{mg} \mathrm{Zn;} 40$ $\mathrm{mg} \mathrm{Mn} ; 10 \mathrm{mg} \mathrm{Cu} ; 0,15 \mathrm{mg} \mathrm{l} ; 0,2 \mathrm{mg}$ Se. Promotores/kg de ração: 0,044 g Tylan 250; 0,1 g antioxidante (Antioxidant).

O experimento foi conduzido em um delineamento de blocos casualizados com quatro repetições por tratamento, representadas por baias coletivas de quatro animais, cujo critério para formação de blocos foi o peso do animais no início do experimento. Como não houve $(P>0,05)$ interação sexo $x$ tratamento em nenhum dos parâmetros avaliados, foi realizada a análise sem considerar o fator sexo para dispor de maior número de graus de liberdade (GL) para o erro experimental, propiciando maior precisão do experimento.

$\mathrm{Na}$ análise de variância dos dados, adotou-se o modelo para o delineamento em blocos casualizados representado simbolicamente por: $\mathrm{y}_{\mathrm{ji}}=\mu+\mathrm{b}_{\mathrm{j}}+\mathrm{t}_{\mathrm{i}}+\mathrm{e}_{\mathrm{ji}}$, em que: $y_{\mathrm{ji}}$ é o valor observado da variável resposta pertencente à baia $\mathrm{ji}, \mathrm{j}=1, \ldots, 4$, blocos; $\mathrm{i}=1,2, \ldots, 8$ tratamentos; $\mu$ é a estimativa da média geral da 
resposta no experimento; $b_{j}$, efeito do bloco $j ; t_{i}$, efeito do tratamento $\mathrm{i} ; \mathrm{e}_{\mathrm{ji}}$, erro experimental.

Posteriormente foram testados os seguintes contrastes: T34 X T78 (avaliar se há diferença entre dietas sem FAD e dietas com FAD, ambas na presença de fitase e na ausência do fosfato bicálcico), T14 X T57 (avaliar se há diferença entre dietas sem FAD e dietas com FAD, na ausência de fitase e presença de fosfato bicálcico ou na presença de fitase e ausência de fosfato bicálcico), T1 X T34 (avaliar se existe diferença entre usar fitase e usar fosfato bicálcico em dietas sem FAD), T5 X T78 (avaliar se existe diferença entre usar fitase e usar fosfato bicálcico em dietas com FAD) e T6 X T78 (avaliar se existe diferença entre uma dieta com FAD, sem fosfato bicálcico e sem fitase, em relação à mesma dieta com os diferentes níveis de fitase).

Estes contrastes, que envolvem comparações múltiplas, duas a duas, foram julgados pelo teste t e o efeito de tratamentos e dos contrastes principais foram julgados pelo teste $F$. Toda análise foi realizada através do pacote do SAS (1990).

\section{Resultados e Discussão}

Foi observado pelo teste $\mathrm{F}$ que não houve efeito da fitase $(\mathrm{P}>0,05)$ em dietas sem FAD $(\mathrm{T} 1, \mathrm{~T} 2, \mathrm{~T} 3 \mathrm{e}$ T4) sobre o desempenho dos animais (Tabela 4).

Esta observação indica que adicionar fitase às dietas a base de milho e farelo de soja é tão eficiente quanto suplementá-las com fosfato bicálcico. Estes resultados estão de acordo com o trabalho realizado por Harper et al. (1997) que não encontraram diferença no desempenho dos suínos em crescimento/ terminação ao serem alimentados com dietas a base de milho e farelo de soja suplementadas com fosfato bicálcico ou com fitase. Os autores adicionaram níveis de 250 e $500 \mathrm{UF} / \mathrm{kg}$. Entretanto, no presente

Tabela 4 - Médias calculadas e erro padrão da média do consumo diário (CD - g/d), ganho diário de peso (GDP - g/d) e conversão alimentar $(C A-g / g)$ da fase de crescimento-terminação dos animais

Table 4 - Calculated average and average standard errors of the daily intake (DI-g/d), weight daily gain (WDG - g/d) and feed:gain $(F / G-g / g)$ in the growing-finishing phases of the animal

\begin{tabular}{|c|c|c|c|}
\hline \multirow[t]{2}{*}{$\begin{array}{l}\text { Tratamentos } \\
\text { Treatments }\end{array}$} & \multicolumn{3}{|c|}{$\begin{array}{l}\text { Variáveis avaliadas } \\
\text { Evaluated parameters }\end{array}$} \\
\hline & $\begin{array}{c}\mathrm{CDM} \pm \mathrm{EP}^{1} \\
D I \pm A E S\end{array}$ & $\begin{array}{c}\mathrm{GDP} \pm \mathrm{EP}^{2} \\
W D G \pm A E S\end{array}$ & $\begin{array}{c}\mathrm{CA} \pm \mathrm{EP}^{2} \\
F / G \pm A E S\end{array}$ \\
\hline $\begin{array}{l}\text { Milho, FS, } 0 \text { UF, } \\
\text { C/FB (T1) }\end{array}$ & $2381 \pm 113^{\mathrm{ab}}$ & $821 \pm 32^{\mathrm{a}}$ & $2,90 \pm 0,08^{c}$ \\
\hline $\begin{array}{l}\text { Milho, FS, } 750 \text { UF, } \\
\text { C/FB (T2) }\end{array}$ & $2345 \pm 47^{\mathrm{ab}}$ & $775 \pm 21^{\mathrm{abcd}}$ & $3,03 \pm 0,03^{\mathrm{abc}}$ \\
\hline $\begin{array}{l}\text { Milho, FS, } 750 \text { UF } \\
\text { S/FB (T3) }\end{array}$ & $2326 \pm 100^{a b}$ & $787 \pm 29^{a b c}$ & $2,95 \pm 0,05^{b c}$ \\
\hline $\begin{array}{l}\text { Milho, FS, 1000UF } \\
\text { S/FB (T4) }\end{array}$ & $2320 \pm 29^{a b}$ & $788 \pm 10^{\mathrm{abc}}$ & $2,95 \pm 0,07^{b c}$ \\
\hline $\begin{array}{l}\text { Milho, FS, FAD, } \\
\text { 0 UF, C/FB (T5) }\end{array}$ & $2236 \pm 67^{b}$ & $741 \pm 10^{\mathrm{cd}}$ & $3,02 \pm 0,09^{a b c}$ \\
\hline $\begin{array}{l}\text { Milho, FS, FAD, } \\
750 \text { UF,S/FB (T6) }\end{array}$ & $2240 \pm 92^{b}$ & $727 \pm 17^{d}$ & $3,08 \pm 0,11^{\mathrm{ab}}$ \\
\hline $\begin{array}{l}\text { Milho, FS, FAD, } \\
750 \text { UF, S/FB (T7) }\end{array}$ & $2498 \pm 79^{a}$ & $798 \pm 13^{a b}$ & $3,13 \pm 0,05^{\mathrm{a}}$ \\
\hline $\begin{array}{l}\text { Milho, FS, FAD, } \\
\text { 1000UF,S/FB (T8) }\end{array}$ & $2385 \pm 114^{\mathrm{ab}}$ & $752 \pm 26^{\mathrm{bcd}}$ & $3,17 \pm 0,06^{\mathrm{a}}$ \\
\hline \multicolumn{4}{|l|}{$\begin{array}{l}\text { Contrastes múltiplos } \\
\text { Multiple contrasts }\end{array}$} \\
\hline T34 X T78 & $(\mathrm{P}=0,0807)$ & $(\mathrm{P}=0,5063)$ & $(\mathrm{P}=0,0025)$ \\
\hline T13 X T57 & $(\mathrm{P}=0,8345)$ & $(\mathrm{P}=0,0777)$ & $(\mathrm{P}=0,0192)$ \\
\hline T1 X T34 & $(\mathrm{P}=0,4685)$ & $(\mathrm{P}=0,1601)$ & $(\mathrm{P}=0,4968)$ \\
\hline T6 X T78 & $(\mathrm{P}=0,0491)$ & $(\mathrm{P}=0,0498)$ & $(\mathrm{P}=0,3533)$ \\
\hline T5 X T78 & $(\mathrm{P}=0,017)$ & $(\mathrm{P}=0,1498)$ & $(\mathrm{P}=0,0827)$ \\
\hline
\end{tabular}

R. Bras. Zootec., v.31, n.5, p.2002-2010, 2002 
experimento, ao avaliar os parâmetros ósseos dos animais (Tabelas 5 e 6) foi encontrada diferença $(\mathrm{P}=0,039)$ entre os tratamentos sem FAD (T1 e T3) para CC, PMSD, QPD e QCaD, ou seja, estas dietas sem suplemento inorgânico e com $750 \mathrm{UF} / \mathrm{kg}$ (T3) ocasionaram redução nestes parâmetros de 3,3\%, $11,4 \mathrm{mg} / \mathrm{kg}^{0,75}, 14,5 \mathrm{mg} / \mathrm{kg}^{0,75} \mathrm{e} 13,8 \mathrm{mg} / \mathrm{kg}^{0,75}$, respectivamente, em relação a dieta controle (T1).

Observamos com este resultado sobre a composição óssea dos animais que há mobilização de cálcio e fósforo do osso para o organismo suprindo a exigência dos animais, não sendo o desempenho afetado. Então, ao se adicionar fitase em dietas à base de milho e farelo de soja, é conveniente observar a relação existente entre a atividade da enzima e sua equivalência com a quantidade de fósforo proveniente do suplemento inorgânico, como descrito anteriormente. Assim, foi encontrado que a adição de 750
$\mathrm{UF} / \mathrm{kg}$ da dieta, mas com a adição de fosfato bicálcico obedecendo a equivalência existente entre a enzima e o suplemento inorgânico (T2), os parâmetros ósseos não foram afetados. Este efeito tornou-se mais evidente ao se avaliar, por intermédio do teste $t$ de médias, o contraste T1 x T34, em que foi estimado que a dieta controle (T1) apresentou respostas superiores em relação às dietas com fitase e sem fosfato bicálcico (T3 e T4) nos parâmetros e em quantidades de: $\mathrm{PMSD}(\mathrm{P}<0,01)$ em $86,45 \mathrm{mg} / \mathrm{kg}^{0,75}, \mathrm{CP}(\mathrm{P}<0,02)$ em $0,28 \%$ e QPD $(P<0,01)$ em $10,35 \mathrm{mg} / \mathrm{kg}^{0,75} \mathrm{e}$ $\mathrm{QCaD}(\mathrm{P}<0,01)$ em $20,55 \mathrm{mg} / \mathrm{kg}^{0,75}$. Estes resultados são discordantes dos observados por O'Quinn et al. (1997). Aqueles autores encontraram que ao suplementar nas dietas baixas em fósforo disponível (sem suplemento inorgânico) com 300e 500 UF/kg houve aumento na CC no metacarpo dos suínos em terminação.

A ação da fitase nas dietas com FAD foi diferen-

Tabela 5 - Médias observadas e erro-padrão da média da concentração de cinzas (CC - \%), concentração de fósforo (CP - \%) e concentração de cálcio (CCa - \%) no metacarpo dos suínos no final do experimento

Table 5 - Observed average and average standard errors of the ashs concentration (AC - \%), phosphorus concentracion (PC - \%) and calcium concentracion ( $\mathrm{CaC}-\%)$ in the metacarpo of the pigs in the end of the experiment

\begin{tabular}{|c|c|c|c|}
\hline \multirow[t]{2}{*}{$\begin{array}{l}\text { Tratamentos } \\
\text { Treatments }\end{array}$} & \multicolumn{3}{|c|}{$\begin{array}{l}\text { Variáveis avaliadas } \\
\text { Evaluated parameters }\end{array}$} \\
\hline & $\begin{array}{l}\mathrm{CC} \pm \mathrm{EP}^{1} \\
A C \pm A E S\end{array}$ & $\begin{array}{l}\mathrm{CP} \pm \mathrm{EP}^{2} \\
P C \pm A E S\end{array}$ & $\begin{array}{l}\mathrm{CCa} \pm \mathrm{EP}^{2} \\
C a C \pm A E S \\
\end{array}$ \\
\hline $\begin{array}{l}\text { Milho, FS, } 0 \text { UF, } \\
\text { C/FB (T1) }\end{array}$ & $55,0 \pm 0,3^{\mathrm{a}}$ & $9,62 \pm 0,05^{\mathrm{a}}$ & $20,01 \pm 0,40 \mathrm{a}$ \\
\hline $\begin{array}{l}\text { Milho, FS, } 750 \text { UF, } \\
\text { C/FB (T2) }\end{array}$ & $54,4 \pm 0,4^{\mathrm{ab}}$ & $9,51 \pm 0,02^{\mathrm{a}}$ & $20,08 \pm 0,17^{\mathrm{a}}$ \\
\hline $\begin{array}{l}\text { Milho, FS, } 750 \text { UF } \\
\text { S/FB (T3) }\end{array}$ & $53,2 \pm 0,7 \mathrm{bc}$ & $9,29 \pm 0,11^{\mathrm{a}}$ & $19,45 \pm 0,20^{\mathrm{a}}$ \\
\hline $\begin{array}{l}\text { Milho, FS, 1000UF } \\
\text { S/FB (T4) }\end{array}$ & $54,4 \pm 0,4^{\mathrm{ab}}$ & $9,39 \pm 0,15^{\mathrm{a}}$ & $19,64 \pm 0,24^{\mathrm{a}}$ \\
\hline $\begin{array}{l}\text { Milho, FS, FAD, } \\
\text { 0 UF, C/FB (T5) }\end{array}$ & $53,6 \pm 0,1^{b c}$ & $9,38 \pm 0,08^{a}$ & $19,73 \pm 0,11^{\mathrm{a}}$ \\
\hline $\begin{array}{l}\text { Milho, FS, FAD, } \\
750 \text { UF,S/FB (T6) }\end{array}$ & $52,6 \pm 0,2^{\mathrm{c}}$ & $9,28 \pm 0,08^{a}$ & $19,12 \pm 0,19^{a}$ \\
\hline $\begin{array}{l}\text { Milho, FS, FAD, } \\
750 \text { UF, S/FB (T7) }\end{array}$ & $53,5 \pm 0,4^{b c}$ & $9,46 \pm 0,06^{\mathrm{a}}$ & $19,19 \pm 0,33^{\mathrm{a}}$ \\
\hline $\begin{array}{l}\text { Milho, FS, FAD, } \\
\text { 1000UF,S/FB (T8) }\end{array}$ & $53,0 \pm 0,5^{\mathrm{c}}$ & $9,21 \pm 0,09^{\mathrm{a}}$ & $19,02 \pm 0,38^{\mathrm{a}}$ \\
\hline \multicolumn{4}{|l|}{$\begin{array}{l}\text { Contrastes múltiplos } \\
\text { Multiple contrasts }\end{array}$} \\
\hline $\begin{array}{l}\text { T34 X T78 } \\
\text { T13 X T57 } \\
\text { T1 X T34 } \\
\text { T6 X T78 } \\
\text { T5 X T78 }\end{array}$ & $\begin{array}{c}(\mathrm{P}=0,3001) \\
(\mathrm{P}=0,75) \\
(\mathrm{P}=0,8856) \\
(\mathrm{P}=0,3662) \\
(\mathrm{P}=0,0839)\end{array}$ & $\begin{array}{c}(\mathrm{P}=0,9899) \\
(\mathrm{P}=0,7068) \\
(\mathrm{P}=0,021) \\
(\mathrm{P}=0,603) \\
(\mathrm{P}=0,695)\end{array}$ & $\begin{array}{l}(\mathrm{P}=0,1395) \\
(\mathrm{P}=0,3512) \\
(\mathrm{P}=0,1904) \\
(\mathrm{P}=0,9677) \\
(\mathrm{P}=0,0872)\end{array}$ \\
\hline
\end{tabular}

\footnotetext{
EP - Erro padrão da média (AES - Average standard errors).

${ }^{1}$ Houve diferença $(P=0,0058)$ entre tratamentos e efeito de fitase $(P=0,0398)$ em dietas sem $F A D$ de acordo com o teste $F$ (There was diference $(P<.0058)$ between treatments and phytase effect $(P=.0398)$ in diets without $D R B$, according to $F$ test).

${ }^{2}$ Não houve diferença entre tratamentos $(P>0,05)$ de acordo com o teste $F$ (There was no diference between treatments $(P>.05)$, according to F test).
}

R. Bras. Zootec., v.31, n.5, p.2002-2010, 2002 
Tabela 6 - Médias observadas e erro padrão da média do peso do metacarpo seco e desengordurado (PMSD - mg/ $\mathrm{kg}^{0,75}$ ), quantidade de fósforo depositado (QPD - $\mathrm{mg} / \mathrm{kg}^{0,75}$ ) e quantidade de cálcio depositado (QCaD - mg/ $\mathrm{kg}^{0,75}$ ) no metacarpo dos suínos no final do experimento

Table 6 - Observed average and average standard errors of the defatted dry metacarpo weight (DDMW - mg/kg 0,75$)$, deposited phosphorus amount (DPA - mg/kg $\left.{ }^{0,75}\right)$ and deposited calcium amount (DCaA - mg/kg.75) in the metacarpo of the pigs in the end of the experiment

\begin{tabular}{|c|c|c|c|}
\hline \multirow[t]{2}{*}{$\begin{array}{l}\text { Tratamentos } \\
\text { Treatments }\end{array}$} & \multicolumn{3}{|c|}{$\begin{array}{l}\text { Variáveis avaliadas } \\
\text { Evaluated parameters }\end{array}$} \\
\hline & $\begin{array}{l}\mathrm{PMSD} \pm \mathrm{EP}^{1} \\
D D M W \pm A E S\end{array}$ & $\begin{array}{l}\mathrm{QPD} \pm \mathrm{EP}^{1} \\
D P A \pm A E S\end{array}$ & $\begin{array}{l}\mathrm{QCaD}^{\mathrm{Q}} \mathrm{EP}{ }^{1} \\
D C a A \pm A E S\end{array}$ \\
\hline $\begin{array}{l}\text { Milho, FS, } 0 \text { UF, } \\
\text { C/FB(T1) }\end{array}$ & $799,1 \pm 14,1^{\mathrm{a}}$ & $76,86 \pm 1,69^{\mathrm{a}}$ & $159,88 \pm 5,57^{a}$ \\
\hline $\begin{array}{l}\text { Milho, FS, } 750 \text { UF, } \\
\text { C/FB (T2) }\end{array}$ & $759,3 \pm 18,6^{\mathrm{ab}}$ & $72,11 \pm 1,60^{\mathrm{ab}}$ & $152,51 \pm 4,78^{\mathrm{ab}}$ \\
\hline $\begin{array}{l}\text { Milho, FS, } 750 \text { UF } \\
\text { S/FB (T3) }\end{array}$ & $708,0 \pm 4,8^{b c d}$ & $65,74 \pm 0,38^{\mathrm{cd}}$ & $137,84 \pm 1,12^{\mathrm{cd}}$ \\
\hline $\begin{array}{l}\text { Milho, FS, 1000UF } \\
\text { S/FB (T4) }\end{array}$ & $717,3 \pm 17,9^{\mathrm{bcd}}$ & $67,27 \pm 0,71^{\text {bcd }}$ & $140,83 \pm 1,93^{\mathrm{bcd}}$ \\
\hline $\begin{array}{l}\text { Milho, FS, FAD, } \\
\text { 0 UF, C/FB (T5) }\end{array}$ & $728,6 \pm 31,7^{\mathrm{bc}}$ & $68,47 \pm 3,43^{b c}$ & $144,04 \pm 6,21^{b c}$ \\
\hline $\begin{array}{l}\text { Milho, FS, FAD, } \\
750 \text { UF,S/FB (T6) }\end{array}$ & $668,2 \pm 6,8^{d}$ & $61,98 \pm 0,68^{d}$ & $127,83 \pm 2,37^{d}$ \\
\hline $\begin{array}{l}\text { Milho, FS, FAD, } \\
750 \text { UF, S/FB (T7) }\end{array}$ & $712,7 \pm 25,6^{\text {bcd }}$ & $67,35 \pm 2,21^{\text {bcd }}$ & $136,72 \pm 5,28^{\mathrm{cd}}$ \\
\hline $\begin{array}{l}\text { Milho, FS, FAD, } \\
\text { 1000UF,S/FB (T8) }\end{array}$ & $701,0 \pm 16,3^{\mathrm{cd}}$ & $64,56 \pm 1,94^{\mathrm{cd}}$ & $133,44 \pm 5,49^{\mathrm{cd}}$ \\
\hline \multicolumn{4}{|l|}{$\begin{array}{l}\text { Contrastes múltiplos } \\
\text { Multiples contrasts }\end{array}$} \\
\hline T34 X T78 & $(\mathrm{P}=0,7690)$ & $(\mathrm{P}=0,77)$ & $(\mathrm{P}=0,3745)$ \\
\hline T13 X T57 & $(\mathrm{P}=0,1061)$ & $(\mathrm{P}=0,0808)$ & $(\mathrm{P}=0,0849)$ \\
\hline T1 X T34 & $(\mathrm{P}=0,0016)$ & $(\mathrm{P}=0,0002)$ & $(\mathrm{P}=0,0018)$ \\
\hline T6 X T78 & $(\mathrm{P}=0,1199)$ & $(\mathrm{P}=0,0933)$ & $(P=0,2207)$ \\
\hline T5 X T78 & $(\mathrm{P}=0,3733)$ & $(\mathrm{P}=0,2789)$ & $(\mathrm{P}=0,1337)$ \\
\hline
\end{tabular}

ciada, ao ser avaliado o contraste T6 x T78, quando se constatou que os tratamentos com fitase (T7 e T8) ocasionaram maior GPD $(\mathrm{P}<0,05)$ dos animais (em torno de $48 \mathrm{~g} / \mathrm{d})$ em relação ao tratamento sem fitase e sem fósforo inorgânico (T6). Foram resultados semelhantes aos apresentados por Han et al. (1997), que encontraram aumento no GPD dos suínos em terminação ao adicionar fitase em dietas sem fósforo inorgânico e com $20 \%$ de farelo de arroz. Além disso, apesar de não ter havido efeito da fitase sobre a CA ao avaliar este mesmo contraste, foi verificado que o tratamento sem fitase e sem suplemento de fósforo inorgânico (T6) consumiram $201 \mathrm{~g} / \mathrm{d}$ a menos $(\mathrm{P}<0,02)$ de ração do que os animais alimentados com os tratamentos T7 e T8. Este resultado foi semelhante aos de O`Quinn et al. (1997), os quais observaram que o consumo dos animais aumentou linearmente ao adicionar fitase $(0,300$ e $500 \mathrm{UF} / \mathrm{kg})$.
Por outro lado, dentre estas mesmas dietas com FAD, não foi encontrada diferença $(\mathrm{P}>0,05)$ entre as dietas suplementadas com fósforo inorgânico e aquelas suplementadas com fitase em todos os parâmetros ósseos avaliados. Todavia, ao comparar a dieta controle com FAD (T5) com a dieta sem fitase e sem suplemento inorgânico (T6), verificou-se que a última ocasionou nos animais redução de $8,3 \%$ no PMSD e de 11,3 e 9,5\% nas QPD e QCaD, respectivamente. Com isso, observou-se que a adição de fitase em dietas contendo ingrediente com alto teor de fósforo total de baixa disponibilidade (FAD) proporcionou aos animais suplemento mineral suficiente para atender as suas exigências e, conseqüentemente, adequada formação óssea. Han et al. (1997) também não verificaram diferença ao comparar dietas com fitase (1200 UF/kg) em relação àquelas contendo suplemento de fósforo inorgânico, e ambas contendo farelo 
de arroz, sobre os ossos metacarpo e metatarso dos suínos abatidos aos $90 \mathrm{~kg}$.

Ao comparar as dietas sem FAD com as dietas com FAD (contraste T13 x T57), foi observado que os primeiros tratamentos foram mais eficientes $(\mathrm{P}<0,02)$ do que os últimos em $0,15 \mathrm{~g} / \mathrm{g}$, em se tratando de CA. Também apenas a dieta controle dos tratamentos sem FAD (T1) foi superior a todas as dietas com FAD (T5, T6, T7 e T8) para GPD $(\mathrm{P}<0,03), \mathrm{CC}$ $(\mathrm{P}<0,01)$, PMSD $(\mathrm{P}<0,01)$, QPD $(\mathrm{P}<0,01)$ e $\mathrm{QCaD}$ $(\mathrm{P}<0,01)$. Provavelmente seja devido ao nível utilizado de FAD e consequentemente ao conteúdo de fibra existente nas quatro últimas dietas. Havendo maior conteúdo de fibra na dieta poderá haver formação de complexos com os minerais, prejudicando assim, a sua absorção (Ferreira, 1994). Adicionalmente ocorre aumento na velocidade da taxa de passagem do alimento no trato gastrointestinal reduzindo a absorção destes nutrientes. Resultado discordante com de Warren \& Farrell (1990), os quais afirmaram que as dietas com até $30 \%$ de FAD resultam em um aceitável desempenho dos suínos quando o consumo de energia digestível for constante.

\section{Conclusões}

Não foi necessária a adição de fosfato bicálcico às rações (sem ou com FAD), quando se adicionou fitase. Isto não é verdadeiro ao avaliar a composição óssea dos animais, exceto nas dietas com FAD.

\section{Agradecimento}

À empresa AVIPAL S.A., que cedeu as instalações e os funcionários para a realização do trabalho experimental. Ao laboratório de análises fisico-químicas da Embrapa Suínos e Aves, pela realização das análises. Ao CNPq - Conselho Nacional de Desenvolvimento Científico e Tecnológico, pela concessão de bolsa de Recém-Doutora. À revisora de português professora Elisabetha Ludke.

\section{Literatura Citada}

ASSADA, K.; KASAI, Z. Formation of myo-inositol and phytin in ripening rice grains. Plant and Cell and Physiology, v.3, n.1, p.28-45, 1962.

ASSOCIATIONOFOFFICIAL ANALYTICALCHEMISTS - AOAC. Official methods of analysis. Washington, D.C.: 1984. 1141p.

CHERYAN, M. Phytic acid interactions in food systems. CRC Critical Revision Food Science and Nutrition, v.13, n.4, p.296-335, 1980.

R. Bras. Zootec., v.31, n.5, p.2002-2010, 2002
EMPRESA BRASILEIRA DE PESQUISA AGROPECUÁRIA EMBRAPA. Tabela de composição química e valores energéticos de alimentos para suínos e aves. 2.ed. Concórdia: Centro Nacional de Pesquisa de Suínos e Aves, 1985. 28p.

FERREIRA, W.M. Os componentes da parede celular vegetal na nutrição de não-ruminantes. In: SIMPÓSIO INTERNACIONAL DE PRODUÇÃO DE NÃO-RUMINANTES DA REUNIÃO ANUAL DA SOCIEDADE BRASILEIRA DE ZOOTECNIA, 31., 1994, Maringá. Anais... Maringá: Sociedade Brasileira de Zootecnia, 1994. p.85-113.

FICK, K.R.; MILLER, S.M.; FUNK, J.D. et al. Métodos de determinação de minerais em tecidos animais e plantas. Gainesville: University of Florida, 1976. 62p.

HAN, Y.M.; YANG, F.; ZHOU, A.G. et al. Supplemental phytases of microbial and cereal source improve dietary phytate phosphorus utilization by pigs from weaning through finishing. Journal of Animal Science, v.75, n.4, p.1017-1025, 1997.

HARPER, A.F.; KORNEGAY, E.T.; SCHELL, T.C. Phytase supplementation of low-phosphorus growing-finishing pig diets improves performance phosphorus digestibility and bone mineralization and reduces phosphorus excretion. Journal of Animal Science, v.75, n.12, p.3174-3186, 1997.

KORNEGAY, E.T. Phytase in poultry and swine phosphorus management. In: EASTERN NUTRITION CONFERENCE, 1996, Ottawa. Proceedings... Ottawa: CFIA, 1996. p.71-113.

LIU, J.; BOLLINGER, D.W.; LEDOUX, D.R. et al. Lowering the dietary calcium to total phosphorus ratio increases phosphorus utilization in low-phosphorus corn-soybean meal diets supplemental with microbial phytase for growing-finishing pigs. Journal of Animal Science., v.76, n.3, p.808-813, 1998.

MILLER, E.R.; ULLREY, D.E.; LEWIS, A.J. Swine nutrition. London: Butterworth-Heinemann, 1991. 673p.

NATIONAL RESEARCH COUNCIL - NRC. Nutrient requirements of swine. 9.ed. Washington, D.C.: National Academy of Sciences, 1988. 90p.

NEWMAN, K. Phytase: the enzyme, its origin and characteristics. Impact and potencial for increasing phosphorus availability. In: ALLTECH'S ANNUAL SYMPOSIUM OF BIOTHECHNOLOGY IN THE FEED INDUSTRY, 7., 1991, Nicholasville. Proceedings... Nicholasville: 1991. p.169-177.

OLIVEIRA, R.L.; MOLINA, C.S. Farelos vegetais. Companhia de silos e armazéns. Porto Alegre: CORAG, 1981. 20p.

O'QUINN, P.R.; KNABE, D.A.; GREEG, E.J. Efficacy of Natuphos in sorghum-based diets of finishing swine. Journal of Animal Science, v.75, n.5, p.1299-1307, 1997.

QUIAN, H.; KORNEGAY, E.T.; CONNER Jr., D.E. Adverse effects of wide calcium:phosphorus ratios on supplemental phytase. Efficacy for wealing pigs fed two dietary phosphorus levels. Journal of Animal Science, v.74, n.6, p.1288-1297, 1996.

SANDBERG, A.S.; LARSEN, T.; SANDSTRÖM, B. High dietary calcium level decreases colonic phytate degradation in pigs fed a rapeseed diet. Journal of Nutrition, v.123, n.1, p.559-566, 1993.

SAS INSTITUTE. User's guide: statistic, version 6.4. v.2, Cary: 1990. 1686p.

WARREN, B.E.; FARRELL, D.J. The nutritive value of full-fat and defatted Australian rice bran. II. Growth studies with chickens, rats and pigs. Animal Feed Science and Technology, v.27, n.3, p.229-246, 1990.

Recebido em: 19/06/01 Aceito em: 09/07/02 